\title{
ESTIVAÇÃO DE BIOMPHALARIA TENAGOPHILA (PULMONATA, PLANORBIDAE)
}

\author{
Horacio Manuel Santana Teles* \\ Cristiano Correa de Azevedo Marques*
}

\begin{abstract}
TELES, H.M.S. \& MARQUES, C.C. de A. Estivação de Biomphalaria tenagophila (Pulmonata, Planorbidae). Rev. Saúde públ., S.Paulo, 23:76-8, 1989.

RESUMO: É relatado o encontro de Biomphalaria tenagophila estivada, em dois municípios do Estado de São Paulo (Brasil): Ubatuba e Conchas. Essa característica etológica foi percebida em 15 exemplares coletados em Ubatuba e $6 \mathrm{em}$ Conchas. Os caramujos estavam enterrados em fendas do solo ressecado,e, em laboratório, voltaram a exibir vitalidade depois de colocados em água.
\end{abstract}

DESCRITORES: Biomphalaria tenagophila. Estivação. Esquistossomose mansônica, prevenção. Ecologia de vetores.

A estivação é um comportamento de certas espécies quando ficam frente a determinadas adversidades ambientais. No que diz respeito aos moluscos pulmonados, resulta quase sempre de uma proteção contra o secamento temporário dos habitats, com a passagem para o estado de dormência ou quiescência sem perda da vitalidade. Com o retorno de condiçōes favoráveis, os individuos estivados são capazes de retornar as atividades normais. Sabe-se do expediente da estivação entre representantes das famílias Planorbidae, Lymnaeidae e Physidae há mais de 150 anos (Pelseneer ${ }^{8}$ ).

Entre os planorbideos a estivação foi bem observada em Biomphalaria glabrata (Say, 1818), acompanhada da produção de lamelas no interior da abertura das conchas (Paraen$\left.\mathrm{se}^{4}\right)$. Richards $9,10,11$ confirmou a formação das lamelas em jovens dessecados de $B$. glabrata, associando o fenômeno à herança multifatorial $^{12}$. Essas estruturas também foram descritas em Biomphalaria schrammi (Crosse, 1864), junto com algumas alterações anatômicas que, de acordo com Paraense e Deslandes ${ }^{6}$ e Paraense e col. ${ }^{7}$, são fruto da inatividade mantida pela espécie durante a sêca. Outras investigações sobre a capacidade de resistência das bionfalárias ao dessecamento, foram conduzidas por Olivier e Barbosa ${ }^{3}$ com Biomphalaria straminea (Dunker, 1848). Embora a presença das lamelas possa ser vinculada com o dessecamento, outras es- pécies, como Biomphalaria obstructa (Morelet, 1849) e Biomphalaria helophila (d'Orbigny, 1835), portam essas deposiçðes conquilíferas, sem que se saiba da ocorrência de estivação entre elas. Afora as bionfalárias, existem registros sobre a estivação de Drepanotrema heloicum (d'Orbigny, 1835)' e Drepanotrema hoffmani Baker, 1945 (Richards ${ }^{9}$ ). Dentre os limneídeos merece destaque o estudo de Gomes e col. ${ }^{2}$ sobre a resistência de Lymnaea columella (Say, 1817) ao dessecamento.

De uma maneira geral os estudos sobre a resistência ao dessecamento são importantes, particularmente quando tratam das bionfalárias transmissoras da Schistosoma mansoni Sambon, 1907, uma vez que essa característica etológica pode dificultar parte das ações desenvolvidas no controle da esquistossomose, como por exemplo as coletas de caramujos, avaliações densitárias, além de reduzir a eficácia das aplicaçōes de moluscicidas solúveis, devido a possibilidade de manter um certo número de indivíduos livres do contato com essas substâncias (Richards ${ }^{11}$ ); também seria necessário rever a importância do esvaziamento de criadouros como medida profilática que constantemente é preconizada. Considerando essas premissas, é apresentado o primeiro encontro de Biomphalaria tenagophila (d'Orbigny, 1835) naturalmente estivada, seguido de uma rápida discus- 
säo das circunstâncias que envolveram a descoberta.

Durante o levantamento da fauna malacológica límnica do Estado de São Paulo (Brasil) realizado pela Superintendência de Controle de Endemias (SUCEN), de 108 exemplares de moluscos procedentes de três localidades dos municípios de Ubatuba (Bairro da Enseada) e Conchas (Bairro dos Aflitos e Bairro Tomazela), 21 foram colhidos em fendas do solo ressecado pela estiagem, ao longo de coleções com o volume hídrico reduzido. Do primeiro município, 15 exemplares estivados foram examinados no laboratório do Serviço Regional de Taubaté da SUCEN, e do segundo, 6 exemplares foram encaminhados ao Laboratório de Malacologia de São Paulo (Capital). Todos os caramujos chegaram aos laboratórios 3 dias após as coletas, feitas em novembro de 1983 e setembro de 1984, respectivamente. Na localidade do Bairro da Enseada (Ubatuba), logo ao início do ano de 1983, foi diagnosticada a eliminação de cercárias de $S$. mansoni (SUCEN ${ }^{14}$ ). Após a pesagem e colocação dos caramujos em água, depois de 24 horas em média, todos os exemplares exibiam vitalidade. Diariamente, pesados durante uma semana, não apareceram alterações significativas da massa corpórea, mostrando que aparentemente a depleção é contornada de maneira satisfatória por $B$. tenagophila. Os individuos orignários de Conchas, já no dia seguinte, cfetuavtin posturas, indicando a fecundação anterior à dessecação e estivação. A descendência obticia no laboratório será objeto de um estudo mais detalhado no assunto.

Com as observações preliminares, é factível afirmar que algumas populações de $B$. tenagophila estejam adaptadas ao dessecamento temporário, ajustadas com a estivação, como acontece com B. glabrata, B. straminea, B. schrammi e outras espécies de pulmonados. Sendo assim a espécie mostra a capacidade de proliferar em ambientes límnicos submetidos à estiagem estacional, ao contrário do que julgava Paraenses, quando ao interpretar as informações disponíveis à época, concluiu que $B$. tenagophila só colonizava corpos d'água permanentes.

A análise dos dados registrados na literatura leva a crer que seja pequena a probabilidade da existência de uma relação única entre a formação de lamelas e a estivação, pressuposto consubstanciado pela inexistência destas estruturas nos exemplares de $B$. tenagophila que foram encontrados em estivação natural. Outros pulmonados capazes de permanecer certos períodos fora d'água, também não apresentam lamelas. Pode ser que a função de sustentação sugerida por Richards ${ }^{10}$, para o caso de $B$. glabrata, não seja fundamental para a resistência ao dessecamento, até porque, as lamelas não aparecem em todas as populações de $B$. glabrata resistentes ao dessecamento (Sturrock ${ }^{13}$ ). É bem mais provável que a formação da camada de muco fechando a abertura das conchas percebida nas espécies aptas para a estivação, referida por Richards ${ }^{9}$, também presente em $B$. tenagophila, detenha papel significativo para a sobrevivência, evitando a perda excessiva de humores.

Para finalizar, diante da possibilidade de estivação demonstrada pelos transmissores de $S$. mansoni, seria prudente que os programas de controle da esquistossomose desenvolvidos em regiôes submetidas à estiagem estacional, orientassem para a realização de coletas dos planorbídeos para a redondeza dos ambientes com o volume hídrico reduzido e leitos sêcos. É quase certo que a volta das condições favoráveis ao repovoamento e a permanência dos portadores humanos da parasitose repõem logo os riscos de contágio. Outra consequêencia da resistência ao dessecamento, seria a ampla distribuição geográfica das espécies dotadas dessa habilidade, sobretudo dos hospedeiros intermediários da endemia, como se dá com B. tenagophila.

TELES, H.M.S. \& MARQUES, C.C. de A. IAestivation in Biomphalaria tenagophila (Pulmonata, Planorbidae). Rev. Saúde públ., S.Paulo, 23:76-8, 1989.

ABSTRACT: This study reports the finding of Biomphalaria tenagophila naturally aestived in two municipalities of the State of S.Paulo (Brazil): Ubatuba and Conchas. This ethological characteristic was discovered in 15 specimens collected in Ubatuba, and in 6 specimens collected in Conchas. The snails aestived showed vitality after bling placed in water.

KEYWORDS: Biomphalaria tenagophila. Estivation. Schistosomiasis mansoni, prevention and control. Ecology, vectors. 


\section{REFERENCIAS BIBLIOGRÁFICAS}

1. D'ORBIGNY, A. Voyage dans l'Amérique méridionale. 3! partie: Mollusques. Paris, P. Bertrand, 1835. v. 5.

2. GOMES, P.A.C. et al. Biologia de Lymnaea columella Say, 1817 (Mollusca, Gastropoda, Basommatophora, Lymnaeidae). Arq. Mus. nac., Rio de Janeiro, 55:67-70, 1975.

3. OLIVIER, R. \& BARBOSA, F.S. Seazonal studies on Tropicorbis centimetralis in northeastern Brazil. Publ. avulsas Inst. Aggeu Magalhaes, 4:105-15, 1955.

4. PARAENSE, W.L. Apertural lamellae in Australorbis glabratus. Proc. Malacol. Soc. London, 32:175-9, 1957.

5. PARAENSE, W.L. Planorbideos hospedeiros intermediários de Schistosoma mansoni. In: Cunha, A.S. da, org. Esquistossomose mansoni. Săo Paulo, Sarvier/EDUSP, 1970. p. 13-30.

6. PARAENSE, W.L. \& DESLANDES, N. Observations on Australorbis janeirensis. Rev. bras. Biol., 16:81-102, 1956.

7. PARAENSE, W.L.; FAURAN, P.; COURMES, E. Observations sur la morphologie, la taxonomie, la répartition géographique et les gîtes d'Autralorbis schrammi. Bull.Soc.Pathol. exot., 57:1236-54, 1964.

8. PELSENEER, P. Essai d'ethologie d'après l'étude des molluques. Bruxelles, Palais Académies, 1935.
9. RICHARDS, C.S. Apertural lamellae, epiphragms, and aestivation of planorbid mollusks. Amer.J.trop.Med. Hyg., 12:254-63, 1963.

10. RICHARDS, C.S. Apertural lamellae as supporting structures in Australorbis glabratus. Nautilus, 78:57-60, 1964.

11. RICHARDS, C.S. Estivation of Biomphalaria glabrata (Basommatophora: Planorbidae): association characteristics and relation to infection with Schistosoma mansoni. Amer. J. trop. Med. Hyg., 16:797-802, 1967.

12. RICHARDS, C.S. Aestivation of Biomphalaria glabrata (Basommatophora, Planorbidae). Genetic studies. Malacologia, 7:109-16, 1968.

13. STURROCK, R.F. An investigation of some factors influencing the survival of St. Lucian Biomphalaria glabrata deprived of water. Ann.trop. Med. Parasit., 64:365-71, 1970.

14. SUPERINTENDENCIA DE CONTROLE DE ENDEMIAS. Programa de Controle da Esquistossomose Mansónica no Estado de São Paulo (Relatório Anual). São Paulo, Secretaria de Estado da Saúde, 1983.

Recebido para publicação em 26/4/1988 Reapresentado em $16 / 11 / 1988$ Aprovado para publicação em 19/11/1988 